\title{
A Product-oriented Approach to Units of Translation in Iranian English- Persian Literary Translations
}

\author{
Esmaeel Ali Salimi \& Zohreh Shahrestani \\ Mofid University
}

\begin{abstract}
The notion of 'unit of translation' as a challenging issue in Descriptive Translation Studies (DTS) is addressed. Considering this notion from a product-oriented point of view as "the TT unit that can be mapped onto a ST unit" (Baker 2001: 286), the main concern here is to investigate a hierarchy of units of translation (UTs) proposed by Newmark (1991: 66-68) including word, phrase, clause, sentence, and paragraph in the literary translations. At the preliminary stage, two questions were raised to detect the most frequent UT adopted by the professional literary translators, and to explore the relationship between the UTs and the free-literal dichotomy in terms of the occurrence of unit/rank shifts. To this end, a corpus of three famous English novels (originally written in English by the renowned authors) and two best-selling translations of each (done by professional translators) were chosen to be analyzed. Through a contrastive analysis, two hundred and ten coupled pairs of ST-TT segments were extracted from the first ten pages of each novel and its two translations based on establishing relations of equivalence between the ST-TT segments and adopting sentence as the major unit of analysis. The UTs adopted in the STTT segments were then identified. The obtained results of the UT
\end{abstract}


categories demonstrated that the most frequent UT adopted by the professional literary translators was sentence. The unit-shifts applied in the UTs were also signified. The statistical calculation of frequency of unit-shifts in each translator's UTs proved that the more frequent is the occurrence of unit-shifts in the UTs of the translator, the more deviated is his translation from the formal correspondence, the more different the size of his UTs is, and finally the freer his translation will be.

Keywords: Descriptive Translation Studies (DTS), units of translation, free-literal dichotomy, unit/rank shifts, equivalence, formal correspondence

\section{Introduction}

Translation Studies is a new discipline concerned with the study of the theory and phenomena of translation. A classical concern for translation theory, frequently mentioned in older literature on the subject, is the level at which equivalence should be established, i.e. what units of translation one should choose during the translation process. Catford suggests that the goal of translation theory is to define the nature of translation equivalence:

The central problem of translation practice is that of finding TL translation equivalents. A central task of translation theory is that of finding the nature and conditions of translation equivalents.

In translation studies, much discussion in the translation literature has focused on identifying what should be equivalent in a translation. For example, with regard to the linguistic form, discussion in translation literature has focused on whether equivalence is to be 
pursued at the level of words, clauses, phrases, sentences, paragraphs, or the entire text. Accordingly, this has given rise to the emergence of the concept of Translation Units, one of the key concepts in translation theory that has exercised translation theorists over a very long period. In the field of translation, from a productoriented approach, a translation unit is a segment of a target text which the translator treats as a single cognitive unit. The translation unit may be a single word, or it may be a phrase, a clause, a sentence, or even a larger unit like a paragraph.

In translation studies, the issue of UT is frequently raised in conjunction with that of translation equivalence. As Sager (1994: 222) puts it, both "lie at the heart of any theoretical or practical discussion about translation". This is because theorists, consciously or unconsciously, take the UT as a compartment in which what they believe to be "translation equivalence" materializes.

There is a point in establishing equivalence, Toury believes, only insofar as it can serve as a stepping stone to uncovering the overall concept of translation underlying the corpus it has been found to pertain to; besides, the notion of equivalence may also facilitate the explanation of the entire network of translational relationship and the individual coupled pairs as representing actual translation units under the dominant norm of translation equivalence (1995: 86). In this regard, one of the tasks of the researcher wishing to probe into the translation units is to establish the equivalent relationships between the coupled pairs of ST and TT segments which can pave the way for the identification and classification of units of translation at different levels. In other words, to investigate unit(s) of translation that the translator chooses during the translation process, one needs to establish a relation of equivalence between the ST and the TT.

In earlier work on translation equivalence, Catford (1965: 20) defines translation as "the replacement of textual material in one language (SL) by equivalent textual material in another language 
(TL)." He distinguishes textual equivalence from formal correspondence, which are respectively called by Nida as dynamic equivalence and formal equivalence. A formal correspondent is "any TL category (unit, class, structure, element of structure, etc.) which can be said to occupy, as nearly as possible, the "same" place in the "economy" of the TL as the given SL category occupies in the SL". A textual equivalent is "any TL text or portion of text which is observed on a particular occasion... to be the equivalent of a given SL text or portion of text" (ibid. 27).

It is worth mentioning, however, that departures from formal correspondence between the source and target texts denote Translation Shifts (ibid. 73), the investigation of which has a longstanding tradition in translation studies. In other words, shifts are deviations or changes that occur at every level during the translation process as a result of the systemic differences between the source and target languages.

There has been a great deal of disagreement about the length (size) of unit of translation. For most, the length of translation units is an indication of proficiency, with professional translators working with larger units (sentence, discourse, or text) and moving more comfortably between different unit levels. This controversy about the length of a unit of translation is, according to Newmark (1988: 54), a concrete reflection of an age-old conflict between free and literal translation: the freer the translation, the longer the UT, and the more literal the translation; the shorter the UT, the closer to the word. Therefore, despite major shifts of viewpoint on translation, one of the oldest as well as the most decried conflicts in translation has been the concept of literal versus free translation, or the distinction between word-for-word translation and sense-for-sense translation. The controversy over "literal" versus "free" translation has a long history, with convincing supporters on each side. 


\section{Research Questions}

In this research, the issue of units of translation is approached from a product-oriented viewpoint to seek answers for the following two questions:

$\mathrm{RQ}_{1}$ : What is the most frequent UT among the professional translators of the famous English novels?

$\mathrm{RQ}_{2}$ : What is the relationship between the UTs and the kinds of translation, i.e. free vs. literal, adopted by the professional literary translators in terms of the occurrence of unit-shifts?

This research is, in fact, an attempt to find answers to these questions. Hence, some main translation issues related to the framework of the research, including descriptive translation studies, translation units, equivalence, dynamic vs. formal equivalence, shift, unit/rank shift, and literal vs. free translation have been theoretically discussed in the following part according to the notions of some famous translation scholars, so that proper answers to the abovementioned questions may be provided.

\section{Theoretical Framework}

Descriptive Translation Studies (DTS), in which the notion of 'unit of translation' is addressed as a challenging issue, is a branch of Translation Studies developed in most detail by Toury (1995) that involves the empirical, non-prescriptive analysis of STs and TTs with the aim of identifying general characteristics and laws of translation (Hatim and Munday 2004: 338). According to Munday (2001: 10-11), DTS is a branch of 'pure' research in Holmes's map of Translation Studies and has three possible foci: examination of the product, the function, and the process. From these three areas, 
this research examines the notion of 'unit of translation' in terms of the product of translation.

According to Baker (2001: 286), a term 'unit of translation', considered from a product-oriented approach, is defined as "the TT unit that can be mapped onto a ST unit". Newmark (1991: 66-68) assumes the main translation units to be a hierarchy: text, paragraph, sentence, clause, group, word, and morpheme.

Theorists regard 'unit of translation' as a compartment in which translation equivalence materializes. Baker (2001: 77) defines equivalence as the relationship between a ST and a TT that allows the TT to be considered as a translation of the ST in the first place. Vinay and Darbelnet view equivalence-oriented translation as a procedure which "replicates the same situation as in the original, whilst using completely different wording" (cited in Shuttleworth and Cowie, 1997: 51).

Nida (1964, cited in Bassnett 1980: 33) distinguishes dynamic equivalence and formal equivalence as two approaches to translation. The former (also known as functional equivalence) is "the closest natural equivalent to the source-language message" (ibid: 166) and attempts to convey the thought expressed in a source text (at the expense of literalness, original word order, the source text's grammatical voice, etc., if necessary); while the latter (also known as formal correspondence) attempts to render the text word-for-word (at the expense of natural expression in the target language, if necessary). Also, defined by Catford (1965: 27), the former (also known as textual equivalence) is "any TL text or portion of text which is observed on a particular occasion to be the equivalent of a given SL text or portion of text" and the latter is "any TL category (unit, class, structure, element of structure, etc.) which can be said to occupy, as nearly as possible, the same place in the economy of the TL as the given SL category occupies in the SL".

Departures from formal correspondence in the process of going from the SL to the TL are called 'translation shifts' (Catford 1965: 
73), i.e. if translational equivalents are not formal correspondent, shifts occur during the translation process. According to Al-Zoubi and Al-Hassnawi (2001: 2), shifts should be defined positively as the consequence of the translator's effort to establish translation equivalence (TE) between two different language systems. To them, shifts are all the mandatory and optional actions of the translator to which $\mathrm{s} /$ he resorts consciously for the purpose of natural and communicative rendition of an SL text into another language (ibid). Shifts can occur in the units of translation. Catford (1965: 79) calls these kinds of shifts 'unit/rank shifts' and defines them as those departures from formal correspondence in which "the translation equivalent of a unit at one rank in the SL is a unit at a different rank in the TL".

Concerning the controversy over the length of unit of translation, a distinction is made between literal and free translation. Literal, or word-for-word, translation is defined by Robinson as the "segmentation of the SL text into individual words and TL rendering of those word-segments one at a time" (1998, cited in Baker 2001: 125). A literal translation can be defined in linguistic terms as a translation "made on a level lower than is sufficient to convey the content unchanged while observing TL norms" (Barkhudarov 1969, cited in Shuttleworth \& Cowie 1997: 95). In a similar vein, Catford also offers a definition based on the notion of the UT: literal translation takes word-for-word translation as its starting point, although because of the necessity of conforming to TL grammar, the final TT may also display group-group or clause-clause equivalence (1965: 25). Whereas, free translation is also known as sense-for-sense translation, it is a type of translation in which more attention is paid to producing a naturally reading TT than to preserving the ST wording intact (Shuttleworth \& Cowie 1997: 62). Linguistically, it can be defined as a translation "made on a higher level than is necessary to convey the content unchanged while observing TL norms" (Barkhudarov 1969: 11, translated, cited in ibid). In other 
words, the UT in a free translation might be anything up to a sentence (or more) even if the content of the ST in question could be reproduced satisfactorily by translating on the word or group level (ibid). Besides, according to Catford (1965: 25), it is a prerequisite of free translations that they should also be unbounded as regards the rank (or level) on which they are performed. Free translations are thus generally more TL-oriented than literal translations.

\section{Methodology}

Through conducting this research, an attempt has been made to investigate the argument about the problematic nature of units of translation in relation to free and literal translations adopted in English-Persian literary translations regarding the unit-shifts. Put another way, the present research seeks to study translation units that the professional literary translators adopt in the process of translating famous novels from English into Persian, and it is carried out by establishing a relation (of equivalence) between the coupled pairs of ST and TT segments. That is to say, this paper looks to ascertain whether the translated literary texts are the closest natural equivalent to the original message (Nida 1964: 166), i.e. dynamically equivalent, or formally equivalent, while taking into account the dichotomy of free-literal approach to translation in terms of the occurrence of unit-shifts in the UTs. So the approach is limited inasmuch as the researcher has looked at Units of Translation only from the angle of the product of translation.

As a consequence, this research is placed within the framework of Pure Translation Studies in Holmes's map of translation studies (Toury 1995: 10, cited in Munday 2001: 10-12), which actually has Descriptive Translation Studies (DTS) as one of its major branches. In fact, DTS embarks upon examination of the product, the function and the process as three focal points among which the first one is 
highlighted in the course of this research. Since this study is concerned with the product of translation and is a com-parative analysis of several TTs of the same ST, it is a 'descriptive' research. Stated by Farhady, "Through descriptive method, researchers attempt to describe and interpret the current status of phenomena" (2001: 144). Descriptive research is defined by Birjandi \& Mosallanejad (2002: 184-86) as the basis for qualitative research that deals with what is happening now.

So the design of this research is 'descriptive' content analysis. Moreover, this research goes under the heading of 'Qualitative.' A qualitative research explains how all parts work together to form a whole. Patten defines qualitative research as "an effort to understand situations in their uniqueness as part of a particular context. It is not attempting to predict what may happen in the future, but to understand the nature of the setting" (cited in Birjandi and Mosallanejad 2002: 76-7).

Moreover, through several subcategories Farhady $(2001: 144,154)$ represents the descriptive method of research as a "Casual-Comparative" method, which is, in turn, a subcategory of "interrela-tional" methods seemed the most appropriate to the researcher to conduct this research. The research is by nature comparative in that it is aimed at comparing and contrasting pairs of ST and TT segments so as to find the most frequent UT among the professional literary translators and to trace and discover the relationship between their UTs and the kinds of translation, i.e. free vs. literal, applied by them in terms of the occurrence of unit-shifts in UTs in the move from the ST to the TT. Thus, it can be found out that this study falls under a comparative category for research method.

\subsection{Corpus Selection Procedure}

In order for the samples of this research to meet the representativeness criterion, i.e. to be representative of the whole population, 
the selection of materials was based on a non-random sampling criterion which is described by Farhady (2001: 212) as a process of choosing research population when random sampling is not possible. For the sake of choosing certain English-Persian literary works, both the source texts and the target texts were selected based on a purposive sampling which is, according to Farhady (ibid. 212), a procedure for selecting a non-random sampling, and defined by him as "the procedure directed toward obtaining a certain type of members with predetermined characteristics" (ibid).

Taking all these criteria into account, the novels and the translations of each were meticulously selected. These were then supposed to be segmented, compared and contrasted from the viewpoint of units of translation. Indeed, the corpus used in this study is a parallel corpus, that is to say, original English source texts and their translations in Persian. A parallel corpus is defined by Olohan (2004: 24) as "a corpus consisting of a set of texts in one language and their translations in another language".

The English novels were selected based on purposive sampling to fulfill three selection criteria; namely, originally written in English, being regarded as masterpieces, Closely related to each other in terms of genre, and written by renowned authors.

Persian translations were also selected based on purposive sampling to include those consistent with three certain criteria; namely, best-selling Persian translations, being considered as the pick of the numerous existing translations, and done by professional translators.

The final samples are presented in Tables 1, 2, 3, and 4 . 
Table 1. List of English novels

\begin{tabular}{ccccc} 
No. & Novel Title & Author & $\begin{array}{c}\text { Year of the First } \\
\text { Edition }\end{array}$ & $\begin{array}{c}\text { Selected } \\
\text { Pages }\end{array}$ \\
\hline 1 & Heart of Darkness & Joseph Conrad & 1899 & $1-10$ \\
\hline 2 & $\begin{array}{c}\text { Lord of the Flies } \\
\text { William } \\
\text { Golding }\end{array}$ & 1954 & $1-10$ \\
\cline { 1 - 2 } & $\begin{array}{c}\text { Cry, the Beloved } \\
\text { Country }\end{array}$ & Alan Paton & 1948 & $1-10$
\end{tabular}

Table 2. Persian Translations of Heart of Darkness

\begin{tabular}{cccccc} 
No. & Title & Translator & $\begin{array}{c}\text { Year of } \\
\text { the First } \\
\text { Edition }\end{array}$ & $\begin{array}{c}\text { Year of } \\
\text { Publication }\end{array}$ & $\begin{array}{c}\text { Selected } \\
\text { Pages }\end{array}$ \\
\hline 1 & Dele Tariki & $\begin{array}{c}\text { Saleh } \\
\text { Hosseini }\end{array}$ & 1985 & 2001 & $1-10$ \\
\hline 2 & $\begin{array}{c}\text { Dar Amaqe } \\
\text { Zolmat }\end{array}$ & $\begin{array}{c}\text { Fereydon } \\
\text { Hajati }\end{array}$ & 1986 & 1986 & $1-10$
\end{tabular}

Table 3. Persian Translations of Lord of the Flies

\begin{tabular}{ccccc} 
No. Title & Translator & $\begin{array}{c}\text { Year of } \\
\text { the First } \\
\text { Edition }\end{array}$ & $\begin{array}{c}\text { Year of } \\
\text { Publication }\end{array}$ & $\begin{array}{c}\text { Selected } \\
\text { Pages }\end{array}$ \\
\hline $1 \quad$ Ba'le Zabub & $\begin{array}{c}\text { Mahmud } \\
\text { Moshref Azad } \\
\text { (M. Azad) }\end{array}$ & 1984 & 1984 & $1-10$ \\
\hline $\begin{array}{c}\text { Salare } \\
\text { Magas ha }\end{array}$ & $\begin{array}{c}\text { Susan Ardekani } \\
\text { (Shahin) }\end{array}$ & 1984 & 1984 & $1-10$
\end{tabular}


Table 4. Persian Translations of Cry, the Beloved Country

\begin{tabular}{|c|c|c|c|c|c|}
\hline No. & Title & Translator & $\begin{array}{l}\text { Year of } \\
\text { the First } \\
\text { Edition }\end{array}$ & $\begin{array}{c}\text { Year of } \\
\text { Publication }\end{array}$ & $\begin{array}{c}\text { Selected } \\
\text { Pages }\end{array}$ \\
\hline 1 & Benal Vatan & $\begin{array}{c}\text { Simin } \\
\text { Daneshvar }\end{array}$ & 1972 & 1982 & $1-10$ \\
\hline 2 & $\begin{array}{l}\text { Gerye Kon } \\
\text { Sarzamine } \\
\text { Mahbub }\end{array}$ & $\begin{array}{l}\text { Hushang } \\
\text { Hafezipoor }\end{array}$ & 1983 & 2004 & $1-10$ \\
\hline
\end{tabular}

\subsection{Data Collection Procedure}

In order to manage the process of data collection, the first ten pages of each novel and their Persian translations were selected. Then, to make a thorough comparison between the STs and their selected TTs possible, the first two hundred and ten sentences from those ten pages of each novel were extracted. The extracted sentences of each novel were then matched with their two translations. In this way, the ST-TT segments were specified for each novel based on the established equivalent relations. The ST-TT segments extracted from each novel and its two translations were then included in the separate tables related to each novel. Here, a point to mention is that the researcher had to adopt a unit of analysis to make it possible to specify ST-TT segments and later to make it feasible to identify the UTs applied in each segment and, hence, to discover the occurrence of unit-shifts in those UTs.

So, the first stage was to specify the ST segments. For that matter, sentence was basically adopted as the major unit of analysis. Because it is mainly regarded as a meaningful unit that conveys the message completely. Besides, among the language levels the sentence is where sentence linguistics and text linguistics overlap, and decisions made at any other language levels will be duly 
reflected within the contour of the sentence, the primary building block for TL text construction (Hewson \& Martin 1991: 86). However, the researcher encountered some rare cases in each ST (novel) where a complete message was conveyed through a word or phrase, so she considered word or phrase as the minor units of analysis. Moreover, in order to specify the ST segments the researcher had to stick to a punctuation mark to separate the units of analysis; therefore, she essentially used full stops to separate the ST sentences. Because among punctuation signs that operate to (con)textualize, full stops are the most significant marks since they signal the full sentential independence of a language segment (Zhu 1996: 438).

Yet, after specification of the ST segments as mentioned above, the two translations of each ST segment were specified in the next stage. Since the translations were supposed to be specified based on the established equivalent relation between the ST and the TT, the translation column in the tables is entitled 'equivalent translation', which is to Catford (1965: 27) "an empirical phenomenon, discovered by comparing SL and TL texts". Also, it was important to the researcher whether the translation was formally equivalent, i.e. directed more towards the form of the ST or formal correspondence, or dynamically equivalent which is described as "the closest natural equivalent to the source-language message" (Nida 1964: 166). The researcher actually regarded it as a basis to later enable identification of the occurrence of unit-shifts in specified UTs.

\subsection{Data Analysis Procedure}

After specifying the ST-TT segments, they had to be analyzed to see what UT(s) were applied in them by each translator. One source of inspiration for choosing the units of translation was Newmark's (1991: 66-68) statement that assumes the main translation units to be a hierarchy: text, paragraph, sentence, clause, phrase/group, word, 
and morpheme. Yet, in order to increase the degree of manageability of the research, an attempt was made to select those UTs which are frequently preferred as basic working UTs by the translators. Therefore, in ascending order, word, phrase, clause, sentence and paragraph were selected as categories of UT.

\subsubsection{Investigating Units of Translation}

\subsubsection{Word as UT}

It is clear that, despite its apparent convenience, the word on its own is unsuitable for consideration as the basis for a unit of translation. Further, although the researcher has been mostly concerned with the sentence as unit of analysis, there were in fact some rare cases in each story where the researcher had to regard word as UT, because the translator could have successfully conveyed the message to the reader through one word in TT, as in the following cases:

(1) Heavens!

That's right.

Tomorrow, she said.
Khodavandgara!

Aare!

Farda.

\subsubsection{Phrase as UT}

Hatim and Mason (1990: 180) maintain that there is no doubt that translators work with phrases as their raw material, and equivalence cannot truly be established at these levels. Phrase is considered as "two or more words that function together as a group" (Swan 2005: xxii) and conveys a thorough message per se, as in the following cases: 
(2) Old knitter of black wool. Bafandeye pire pashme siyah! "Sucks to your ass-mar!" Folan athmet!

This letter, Stephen. Darbareye in name Estefan.

\subsubsection{Clause as UT}

Syntactically clause forms a part of a sentence and has a subjectpredicate structure which is not complete by itself and is semantically dependent (Richards \& Platt 1992: 52-53); therefore, it is not a meaningful unit and should be completed by another sentence. So this UT has not been separately observed. In fact, the clauses were taken into account in the form of sentences incorporating them, i.e. complex sentences, which contain one or more dependent (or subordinate) clauses and an independent (or main) clause, and compound-complex sentences, which contain two or more independent clauses and one or more dependent clauses (Frank 1972: 1).

In the present study, the clauses have been taken into consideration under two broader constituent categories, i.e. complex sentence or compound-complex sentence. Also, the number of both complex sentences and compound-complex sentences is considered as indicative of clause as UT.

As defined by Frank (1972: 1), a complex sentence contains one or more dependent (or subordinate) clauses and an independent (or main) clause. For example:

(3) They were men enough to face the darkness.

Anha mardanegie in ra dashtand ke ba tariki rurayo shavand.

"I expect there's a lot more of us scattered about.

Gomanam kheili az ma in doro bara pakhsho pala shodan. 
There is a lovely road that runs from Ixopo into the hills. Jaddeye zibaie hast ke az ikopo be tappeha mipeivandad.

Defined by Frank (1972: 1), compound-complex sentence contains two or more independent (or main) clauses and one or more dependent (or subordinate) clauses. For example:

(4) It was the biggest thing in the town, and everybody I met was full of it.

Bozorgtarin chizi bud ke dar in shahr vojud dasht va har kas ra molaqat kardam kamelan az an ettela' dasht.

When he gets leave he'll come and rescue us.

Be mahze inke morakhasi begirad miayad va nejateman midahad.

For there there is a multitude of buses, and only one bus in ten, one bus in twenty maybe, is the right bus.

Anja tarakome otobushast va otobusi ke be maqsade shoma miravad yeki az dah ya bist otobusi ast ke miayad.

\subsubsection{Sentence as UT}

According to Richards and Platt (1992: 330), sentence is the largest unit of grammatical organization within which parts of speech (e.g. nouns, verbs, adverbs) and grammatical classes (e.g. word, phrase, clause) function, and a sentence normally consists of one independent clause with a finite verb. Also, according to Frank (1993: 220), a sentence is a full, independent prediction containing a subject plus a predicate in the form of independent clause. Elsewhere he defines the independent clause as a full prediction that may stand alone as a sentence (222). Based on the independent clause(s) consisting sentences, the sentences can be generally classified into two types: simple and compound, both of which 
contain independent clause as their only building block. So this UT was treated in simple sentences and compound sentences, and the number of both simple sentences and compound sentences is reckoned as indicative of UT as sentence.

According to Frank (1972: 1), a simple sentence contains one full subject and predicate and can take the form of a statement, a question, a request, or an exclamation. Such a sentence has only one full prediction in the form of an independent clause (Frank 1993: 222). For example:

(5) His remark did not seem at all surprising. Goftare Marlo be hich ru maye taajob nagardid.

Piggy bore this with a sort of humble patience. Khuke in harf ra ba forutani va bordbari tahammol kard.

It is not an easy letter.

Nameye sar rasti nist.

Frank (1972: 1) also points out that a compound sentence contains two or more sentences joined into one by punctuation alone, punctuation and a conjunctive adverb, or a coordinate conjunction; when such sentences are joined coordinately, they are each called independent clause. Such sentences have two or more full predictions in the form of independent clauses (1993: 222). For example:

(6) I gave my name, and looked about.

Esmam ra goftam va be doro baram negah kardam.

Ralph giggled into the sand.

Ralph miyane maseha ghalt mizad va mikhandid.

She took the letter and she felt it.

Zan kaghaz ra gereft va lams kard. 


\subsubsection{Paragraph as UT}

Defined by Richards and Platt (1992: 262), paragraph is a unit of organization of written language, which serves to indicate how the main ideas in a written text are grouped. In text linguistics, paragraphs are considered as macro-structure of a text and they group sentences which belong together and deal with the same topic. Consequently, a paragraph, as a macro-structure, usually consists of a_group of related sentences such as simple, compound, complex, or compound-complex which together incorporate a whole unit. Yet, in this study, paragraph as UT was found to be exclusively implemented in the both translations of Heart of Darkness by the same number, and no cases of such UT were found in the both translations of the two other stories. For example:

(7) And at last, in its curved and imperceptible fall, the sun sank low, and from glowing white changed to a dull red without rays and without heat, as if about to go out suddenly, stricken to death by the touch of that gloom brooding over a crowd of men.

Aaqebat ham khorshid dar forude qowsi va na mahsusash paein oftad va chenan ke guei nagahan dar kare raftan bashad va daste tiregie kheyme gostar bar jam'e adamian be halakash andakhte bashad, az sefidie tabnak be sorkhie tond --bi asha'e va garmaii--taghiir yaft.

\subsubsection{Investigating Unit-shifts in the UTs Applied by the Translators}

Based on the categories mentioned above, the UTs applied in the ST-TT segments were identified. Concurrently, while identifying the UTs in the ST-TT segments, unit/rank shifts or those departures from formal correspondence in which "the translation equivalent of 
a unit at one rank in the SL is a unit at a different rank in the TL" (Catford 1965: 79) were also sought after. The unit-shifts were specified to later gauge the relationship between the UT and the free-literal dichotomy.

Apparently, according to Catford, shift is not formally equivalent. In fact, if the SL is imitated exactly in the TL, the result is called formally equivalent translation which is awkward or unnatural, more directed towards the form of the ST, and basically source-oriented. However, to avoid such a translation, the translator may deviate from the ST and move away from close linguistic equivalence, so a shift occurs and the resulting translation distancing from formal correspondence (equivalence) is called dynamically (textually) equivalent translation which is described as "the closest natural equivalent to the source-language message" (Nida 1964: 166).

The kind of shift which is taken into account in the current study is unit/rank shift that is a subdivision of category shift and is defined by Catford (1965, cited in Munday 2001: 61) as the shift "where the translation equivalent in the TL is at a different rank to the SL", as in the following cases:

\begin{tabular}{|c|c|c|c|}
\hline English & Equivalent Translation & UT & Shift \\
\hline Dead in the $c$ & $\begin{array}{c}\text { Dorost ham dar vasate } \\
\text { naqshe bud. }\end{array}$ & $\begin{array}{c}\text { Phrase }=> \\
\text { s.s. }\end{array}$ & ye \\
\hline $\begin{array}{l}\text { For a moment he } \\
\text { looked interested. }\end{array}$ & $\begin{array}{r}\text { Be nazar mi } \\
\text { majara alaqen }\end{array}$ & S.S. & ye \\
\hline Look at & Begir anra negah kon! & S.S. & ye \\
\hline
\end{tabular}

\section{Discussion and Conclusions}

While analyzing the collected data, it seemed logical to calculate the frequency and percentage of units of translation applied in the 
three novels as well as the frequency and percentage of unit-shifts in the UTs adopted by the professional translators of those novels. Based on the findings of the analysis, the results of the statistical analysis are presented in the following tables:

As Table 5 reveals, the most frequently applied unit of translation among the literary translators is the sentence which remarkably includes the majority of samples, the highest frequency as well as the highest percentage which ranks sentence as the top list category and the foremost adopted unit of translation. In addition, clause covering a wide range of samples and having an approximately high frequency and percentage occupies the second prominent position among the applied units of translation. Lastly, phrase, word and paragraph are respectively other applied units of translation whose frequency and percentage are not highly significant.

Table 5. Frequency and Percentage of Units of Translation in Heart of Darkness, Lord of the Flies, and Cry, the Beloved Country

\begin{tabular}{|c|c|c|c|c|c|}
\hline $\begin{array}{c}\text { Total } \\
\text { Percen- } \\
\text { tage } \%\end{array}$ & $\begin{array}{c}\text { Percen } \\
\text {-tage }\end{array}$ & $\begin{array}{c}\text { Total } \\
\text { Frequency }\end{array}$ & $\begin{array}{c}\text { Frequen- } \\
\text { cy }\end{array}$ & $\begin{array}{l}\text { Sub-categories } \\
\text { of Units of } \\
\text { Translation }\end{array}$ & $\begin{array}{l}\text { Units of } \\
\text { Translation }\end{array}$ \\
\hline 1.81 & 1.81 & 24 & 24 & & Word \\
\hline 3.27 & 3.27 & 44 & 44 & & Phrase \\
\hline \multirow[b]{2}{*}{43.18} & 29.48 & \multirow[b]{2}{*}{580} & 396 & $\begin{array}{l}\text { Complex } \\
\text { Sentence }\end{array}$ & \multirow[b]{2}{*}{ Clause } \\
\hline & 13.70 & & 184 & $\begin{array}{l}\text { Compound- } \\
\text { complex } \\
\text { sentence }\end{array}$ & \\
\hline \multirow{2}{*}{51.45} & 31.19 & \multirow{2}{*}{691} & 419 & $\begin{array}{l}\text { Simple } \\
\text { Sentence }\end{array}$ & \multirow{2}{*}{ Sentence } \\
\hline & 20.25 & & 272 & $\begin{array}{l}\text { Compound } \\
\text { Sentence }\end{array}$ & \\
\hline 0.29 & 0.29 & 4 & 4 & & Paragraph \\
\hline
\end{tabular}


This leads to the conclusion that successful literary translators are mostly concerned with the sentence as their unit of translation to find the closest natural equivalent to the source-language message and to best convey the message to the TL reader.

Since the occurrence of unit-shifts, as departures from formal correspondence in the UTs in the move from SL to TL, is the focus of study in this section, here the frequency and percentage of shifts occurred in the UTs of each translator have been calculated separately to make the comparison possible. As indicated in Table 6, unit-shift has occurred most frequently in Ardekani's translation of Lord of the Flies, so it contains the highest percentage. Also, in Hajati's translation of Heart of Darkness a nearly similar number of unit-shifts has occurred. It can be representative of the fact that these two translators are highly oriented towards deviating from the ST, applying translation units of a size different from the ST, and, thus, their translations tend to be freer.

Table 6. Frequency and Percentage of shifts in the UTs in Heart of Darkness, Lord of the Flies, and Cry, the Beloved Country

\begin{tabular}{cccc} 
Novels & Translators & Frequency & Percentage \% \\
Heart of & Hosseini's Translation & 88 & 41.90 \\
\cline { 2 - 4 } Darkness & Hajati's Translation & 97 & 46.19 \\
\hline \multirow{2}{*}{$\begin{array}{c}\text { Lord of the } \\
\text { Flies }\end{array}$} & Azad's Translation & 75 & 35.71 \\
\cline { 1 - 4 } $\begin{array}{c}\text { Cry, the } \\
\text { Beloved } \\
\text { Country }\end{array}$ & Ardekani's Translation & 98 & 46.66 \\
\cline { 2 - 4 } & Daneshvar's Translation & 77 & 36.66 \\
\hline
\end{tabular}

It can be inferred that, as far as the product-oriented view of the UTs is concerned, the more frequent is the occurrence of shifts in the UTs of the translator, the more deviated is his/her translation 
from the formal correspondence, the more different the size of his/her UTs is, and finally the freer his translation will be. Thus, there is a direct relationship between the number of occurrence of shifts in the units of translation (i.e. unit-shifts) and free translation. Besides, although frequency of the occurrence of unit-shifts is closely related to a free translation being produced and it may make a translation freer, it may change the size of the UTs to a longer or shorter UT; so for the UTs it is the matter of either/or.

\section{Conclusion}

The findings, theoretical discussions, as well as practical evidences of this research can provide guidelines for novice translators who need to gain the initial knowledge to take the preliminary steps. Also, the results of this study may introduce some usable hints on the application of the most appropriate UT in the literary translation for university students majoring in translation and translation courses. Since the most frequently applied UT among the literary translators proved to be the 'sentence', grammar exercises and translation tasks on grammatical structures can be used in translation classes. For fulfilling such a purpose, teachers had better use a grammar-oriented approach in their translation classes, especially in courses such as translation principles and methodology, as well as translation of simple texts in general and literary texts in particular. This is due to the fact that the ST segments can have a deep structure and a surface structure whose identification can help apply the UT that is true equivalence of the ST and best fits the translation of literary texts.

Furthermore, based upon the relationship found in this research between the UTs and the free-literal dichotomy in terms of the unit-

shifts, the translation trainees can be instructed that application of unit-shifts in the process of going from the ST to the TT helps them 
to achieve a free translation and that the literary translation needs to undergo deviations from the formal correspondence to meet this requirement.

At the end, given the importance of application of the most appropriate UT in the literary translations, a need is felt for fulfilling further researches into the domain of UT and it is hoped that this study paves the way for other studies in this area.

\section{References}

Al-Zoubi, Q. \& A. Al-Hassnawi. 2001. Constructing a Model for Shift Analysis in Translation. Translation Journal 5.4. Available at URL < http://accurapid.com/journal/18theory.htm>

Baker, M. 2001. The Routledge Encyclooedia of Translation Studies. London: Routledge.

Bassnett, S. 1980/1991. Translation Studies. London and New York: Routledge

Birjandi, P. \& P. Mosallanejad. 2002. Research Methods and Principles. Tehran, Iran: Shahid Mahdavi Publications.

Catford, C. 1965. A Linguistic Theory of Translation. London: Oxford University Press.

Farhady, H. 1995. Research Methods in Applied Linguistics. Tehran: Payame Noor University.

Frank, M. 1972. Modern English: Exercises for Non-native Speakers, Part II. United States of America: Prentice-Hall.

Hatim, B. \& I. Mason. 1990. Discourse and the Translator. London and New York: Longman.

Hatim, B. \& J. Munday. 2004. Translation: An Advanced Resource Book. Routledge: New York.

Hewson, L \& J. Martin. 1991. Redefining Translation: The

Variational Approach. London and New York: Routledge.

Munday, J. 2001. Introducing Translation Studies: Theories and 
Applications. London \& New York: Routledge.

Newmark, P. 1988. A Textbook of Translation. New York, London: Prentice Hall.

Nida, A. 1964. Toward a Science of Translating. Leiden: E. J. Brill.

Olohan, M. 2004. Introducing Corpora in Translation Studies.

London and New York: Routledge.

Richards, C. et al. 1992. Dictionary of Language Teaching and Applied Linguistics. Great Britain: Longman.

Sager, J. 1994. Language Engineering and Translation Consequences of Automation. Amsterdam and Philadelphia: John Benjamins.

Shuttleworth, M. \& M. Cowie. 1997. Dictionary of Translation Studies. Manchester: St. Jerome.

Swan, M. 2005. Practical English Usage (3rd edition). New York: Oxford University Press.

Toury, G. 1995. Descriptive Translation Studies and Beyond. Amsterdam and Philadelphia: John Benjamins.

Zhu, C. 1996. "Climb Up and Look Down: On Sentences as the Key Functional UT (Unit Of Translation) in Text Translation", Proceedings of the 14th World Congress of the Fédération Internationale des Traducteurs (FIT) Vol. 1, 322-343. Melbourne: AUSIT. 